\title{
ANALISA DETEKSI GAMBAR TERMODIFIKASI DENGAN DEVIASI RGB
}

\author{
Heriyanto \\ Jurusan Teknik Informatika UPN "Veteran" Yogyakarta \\ Jl. Babarsari 2 Tambakbayan 55281 Telp(0274) 485323 \\ e-mail : $\mathrm{mr}$ heriyanto skom@yahoo.com
}

\begin{abstract}
Saving picture which one media represent become part of memory or history document. It is possible that very important to personal. Storage media of picture sometimes become important that had been happened a modification about the original picture whitch a document become very valuable because change by other people and than It is very difficult to prove will the truth of data and original picture and modification picture. Modification picture in general to repair or with specific purpose become the picture makes wrong purpose. BRG picture (Blue Red Green) representing base from colour in picture and It can be analyses about the picture change or colour addition or the picture not change. Process checking of original picture is not also pixel but change of colour a picture, can be known also with change of original primary colour of picture with additional colour of picture, so that can be known by effect change of the colour with some analysis which can ascertain colour change or not. How big change of the colour can be calculating with use of primary colour mean, change of blue colour mean, change of green colour mean, change of mean red and also all of them can be combine.
\end{abstract}

\section{Keywords : History, Color, BRG (Blue, Red, Green), Modification, Document, Picture}

Penyimpanan media gambar merupakan penyimpanan yang menjadi bagian catatan atau kenangan dan merupakan dokumen history, kenang-kenagan yang bisa jadi sangat pribadi. Media penyimpanan gambar terkadang menjadi penting diungkap manakala terjadi suatu modifaikasi terhadap keaslian sehingga menjadikan suatu dokumen yang sangat berharga menjadi berubah ditangan seorang yang melakukan perekayasaan sehingga sangat sulit untuk membuktikan akan kebenaran keaslian dan data gambar yang telah termodifikasi. Modifikasi gambar pada umumnya untuk melakukan perbaikan atau dengan tujuan tertentu sehingga dapat juga disalah gunakan. Pada gambar BRG (Blue Red Green) merupakan dasar dari warna suatu gambar dapat dilakukan analisa apakah suatu gambar berubah atau ketambahan warna atau tidak. Pengecekan keaslian suatu gambar juga dilihat tidak hanya pixel saja namun perubahan warna suatu gambar, dapat diketahui juga dengan perubahan warna dasar asli gambar dengan warna tambahan gambar, sehingga dapat diketahui efek perubahan warna tersebut melalui beberapa analisa yang dapat memastikan warna berubah atau tidak. Seberapa besar perubahan warna tersebut dapat di hitung dengan penggunaan rata-rata warna dasar, dilihat perubahan rata-rata warna biru, perubahan ratarata warna hijau, perubahan rata-rata warna merah serta memadukan hitungan dari ketiganya.

Kata kunci : history, warna, efek, BRG (Blue Red Green), modifikasi, dokumen, gambar

\section{PENDAHULUAN}

Media penyimpana gambar merupakan dokumen yang biasa dipakai untuk kenangkenangan, history dan tentunya sangat pribadi. Dokumen gambar tersebut tentunya sangat beresiko manakala dilakukan modifikasi oleh orang yang tidak bertanggung jawab. Perubahan dapat dilakukan berupa modifikasi yang tentunya akan menambah perubahan warna pada gambar aslinya. Perubahan tersebut dapat diidentifkasi dengan menganalisa warna-warna dasar pada gambar yang merupakan kesatuan dari seluruh warna dengan membandingkan beberapa warna darar BRG (Blue Red Green). 


\section{TINJAUAN PUSTAKA}

a. Dalam format semua gamabar digital dalam bentuk bitmap menggambarkan cara yang sama walaupun berbeda sumber aslinya dan memperhatikan parameter utama yang digunakan mendiskripsikan gambar digital, dengan teknik dan standar kompres. Gambar dapat dengan grayscale atau warna. (Guojun Lu:28).

b. Banyak gambar yang telah dioleh dan dimodifikasi dalam rangka untuk memperbaiki kualitas gambar, untuk mengubah dan mengatur gambar sesuai dengan keinginan bahkan gambar dapat dimodifikasi dengan beberapa gambar yang dapat dipadukan sehingga menjadi suatu gambar yang berbeda dari sumbernya. Bertitik tolak dari modifikasi gambar yang dapat dipadukan dengan gambar yang lain maka bagaimana untuk membedakan bahwa suatu gambar terlah terjadi kontaminasi melalui perubahan pixel yang ada sehingga dapat dicari nilainilai deviasi/penyimpangan gambar dari yang awal dengan gambar yang telah diubah dengan bentuk mapun pewarnaannya.(Heriyanto : Jurnal Telematika Volume 9 No. 1, Juli 2012 ISSN 1829-667X).

c. Suatu hak milik deskripsi yang menguraikan property dari individu pixels (atau kelompok pixels) di dalam gambar itu. Contoh property seperti itu meliputi red-green-blue (RGB) nilai-nilai menyangkut pixel (atau mengumpulkan di suatu kelompok pixels), grayscale mengukur di dalam gambar kasus black and white dan seterusnya.(V.S. Subrahmanian:40).

\section{METODE PENELITIAN}

1. Studi Literatur

Penulis mencari sumber pustaka atau dokumen untuk mempelajari permasalahan seperti teori Digital images, sehingga penulis memahami konsep RGB dengan warna dasar Red, Green, dan Blue

2. Analisa

Menggunakan analysis data rata-rata warna merah ( $r e d)$, rata-rata warna hijau (green) dan rata-rata warna biru (blue). Serta memadukan dari masing-masing biner warna merah, hijau dan biru.

\section{HASIL DAN PEMBAHASAN}

Perubahan warna dasar merah, hijau dan biru dapat dilihat perubahannya dengan menghitung setiap rata-rata dari ketiga warna tersebut. memgidentifikasikan data warna dasar pada gambar asli, gambar grayscale mapun gambar yang telah termodifikasi atau gambar yang telah dirubah dapat saling diperbandingkan.

Pada pembuatan tabel mengidentifikasian warna di simpan dalam suatu field dan record yang ada pada tabel yaitu tabel tfotohitung sebagai berikut :

Tabel 1. Hitung dengan tabel tfotohitung

\begin{tabular}{|l|l|l|l|}
\hline Name Fields & Type Data & Size & Keterangan \\
\hline namafile & Text & 255 & Data folder \\
\hline Dokumen1 & Text & 255 & Biner RGB \\
\hline Ratadatax1 & Number & 10 & Blue \\
\hline Ratadatax2 & Number & 10 & Green \\
\hline Ratadatax3 & Number & 10 & Red \\
\hline Ratadatay1 & Number & 10 & Rata-RataBlue \\
\hline Ratadatay2 & Number & 10 & Rata-Rata Green \\
\hline Ratadatay3 & Number & 10 & Rata-Rata Red \\
\hline
\end{tabular}

Pada penyimpanan data warna dapat dilakukan analisa ketiga warna tersebut dengan rata-rata $\mathrm{x} 1$ sebagai warna biru, rata-rata $\times 2$ sebagai warna hijau, rata-rata $\times 3$ sebagai warna merah.

Setelah data tersebut didapat maka langkah selanjutnya adalah mencari masing-masing setiap rata-rata dari data warna tersebut. maka di dapat data dengan disimpan dalam suatu tabel 
tfotohitung pada rata-rata waran biru dengan field ratadatay1, hitung rata-rata warna hijau dengan field ratadatay2, hitung rata-rata warna merah dengan field ratadatay3 seperti pada tabel di atas. Program dijalankan dengan membuka dokumen gambar bmp dengan open data pada program sebagai berikut :

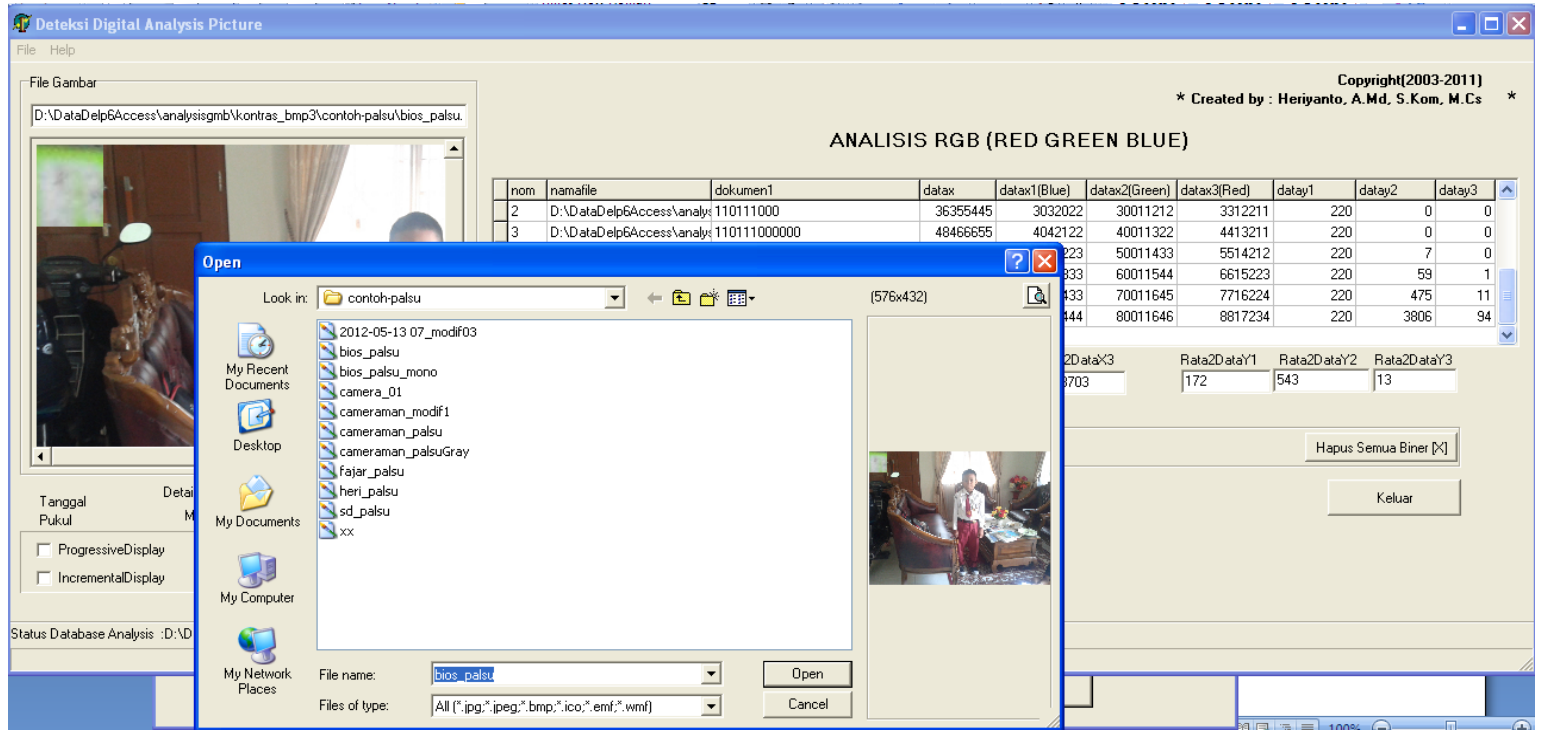

Gambar 1. Membuka file gambar bitmap dengan open folder

Setelah data gambar muncul maka mulai pengambilan warna RGB yang diambil sebagai berikut :

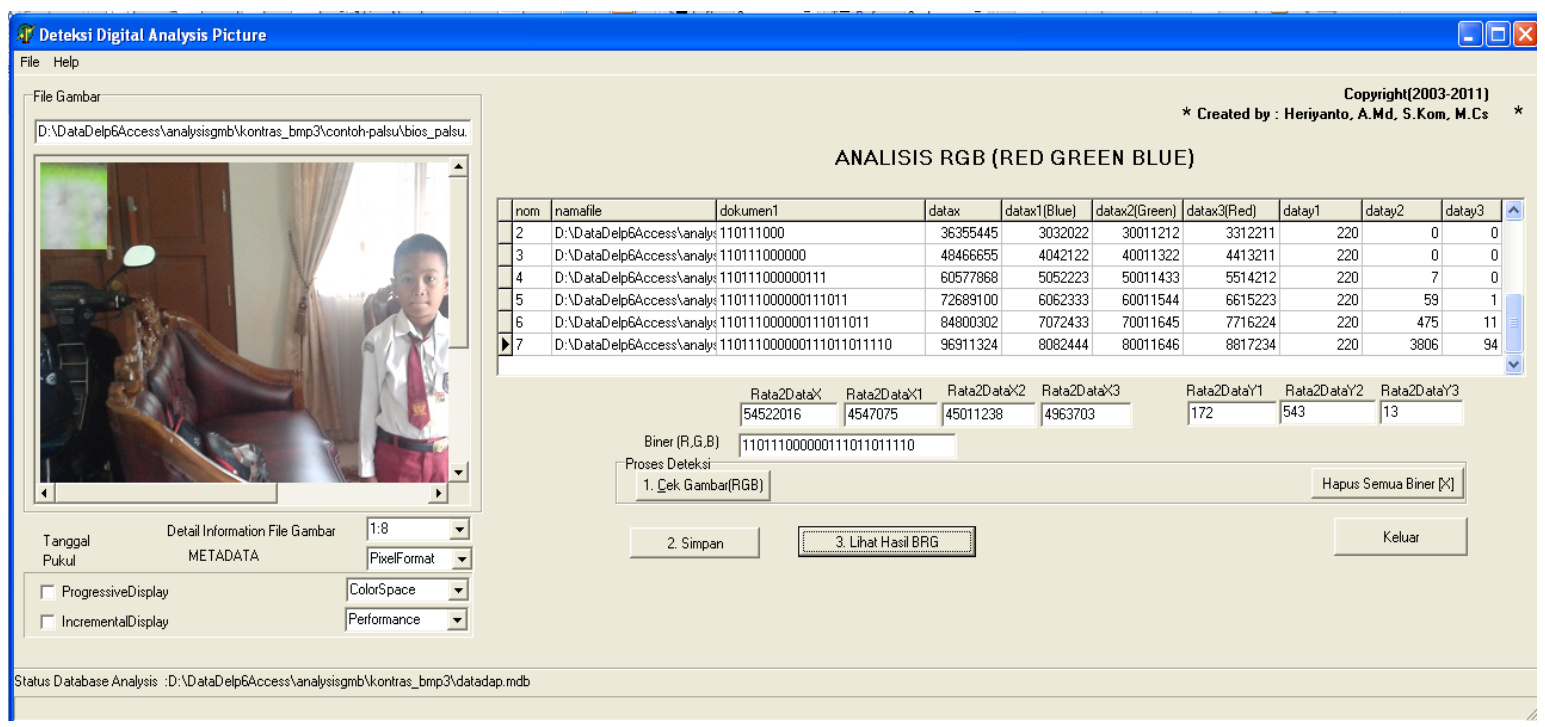

Gambar 2. Proses Pengambilan Warna RGB

Proses selanjutnya ditampilkan hasil rata-rata setiap gambar sebagai berikut : 


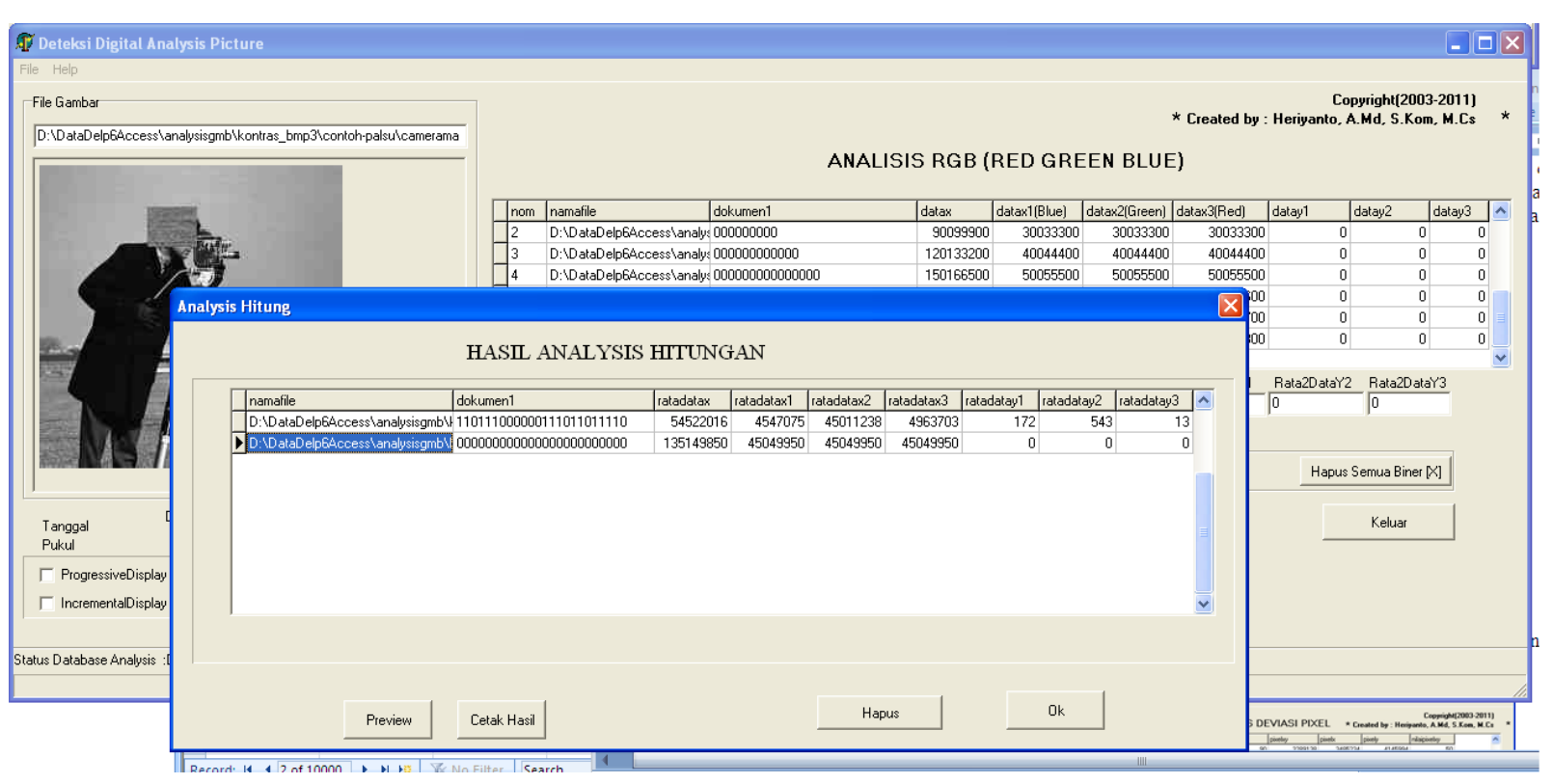

Gambar 3. deteksi cek RGB gambar

Dalam bentuk laporan hasil analisa didapat sebagai berikut :

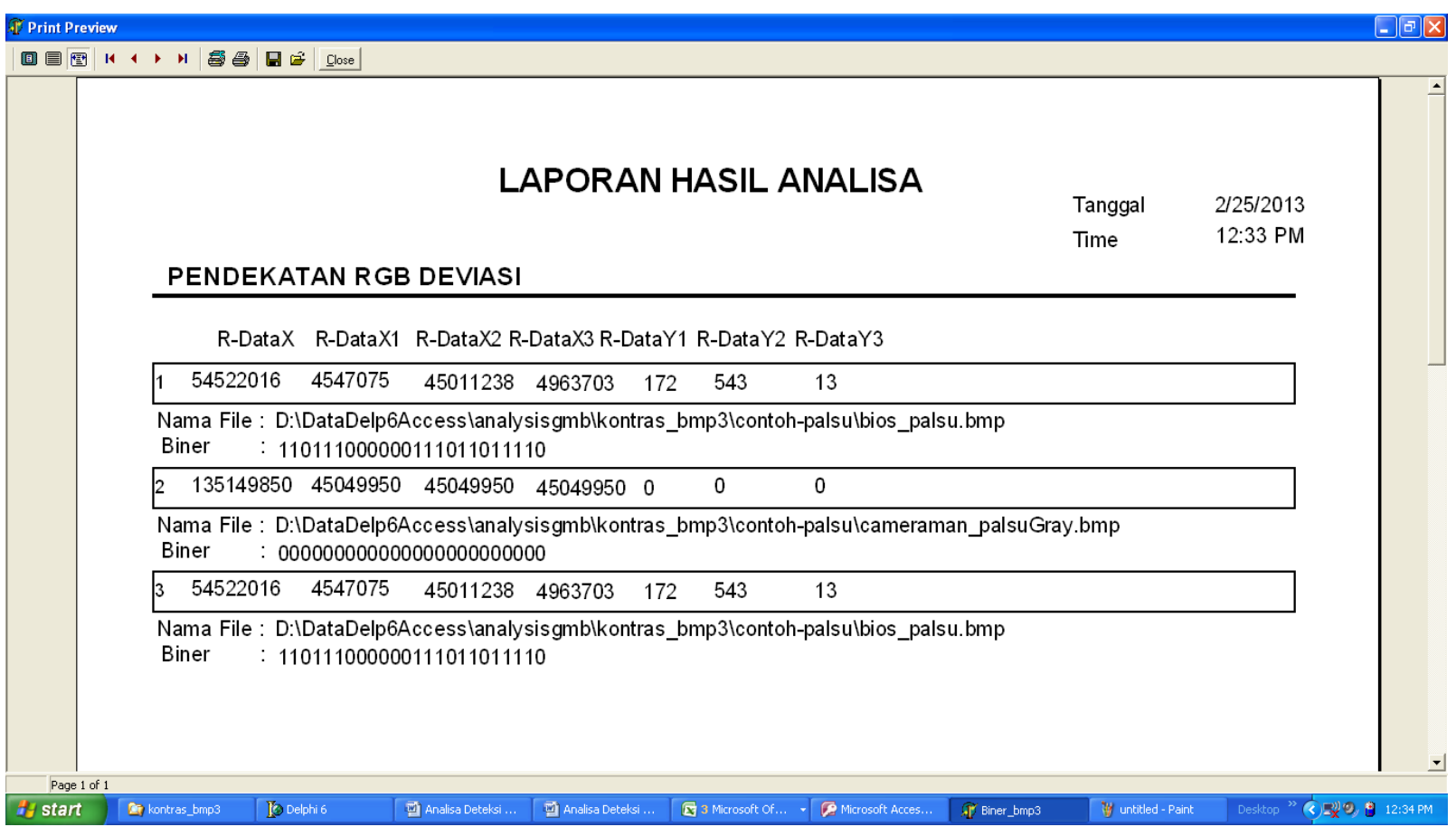

Gambar 4. Tampilan Laporan Hitungan Rata-Rata RGB Analysis

Dalam suatu proceder cek gambar sebagai berikut : 


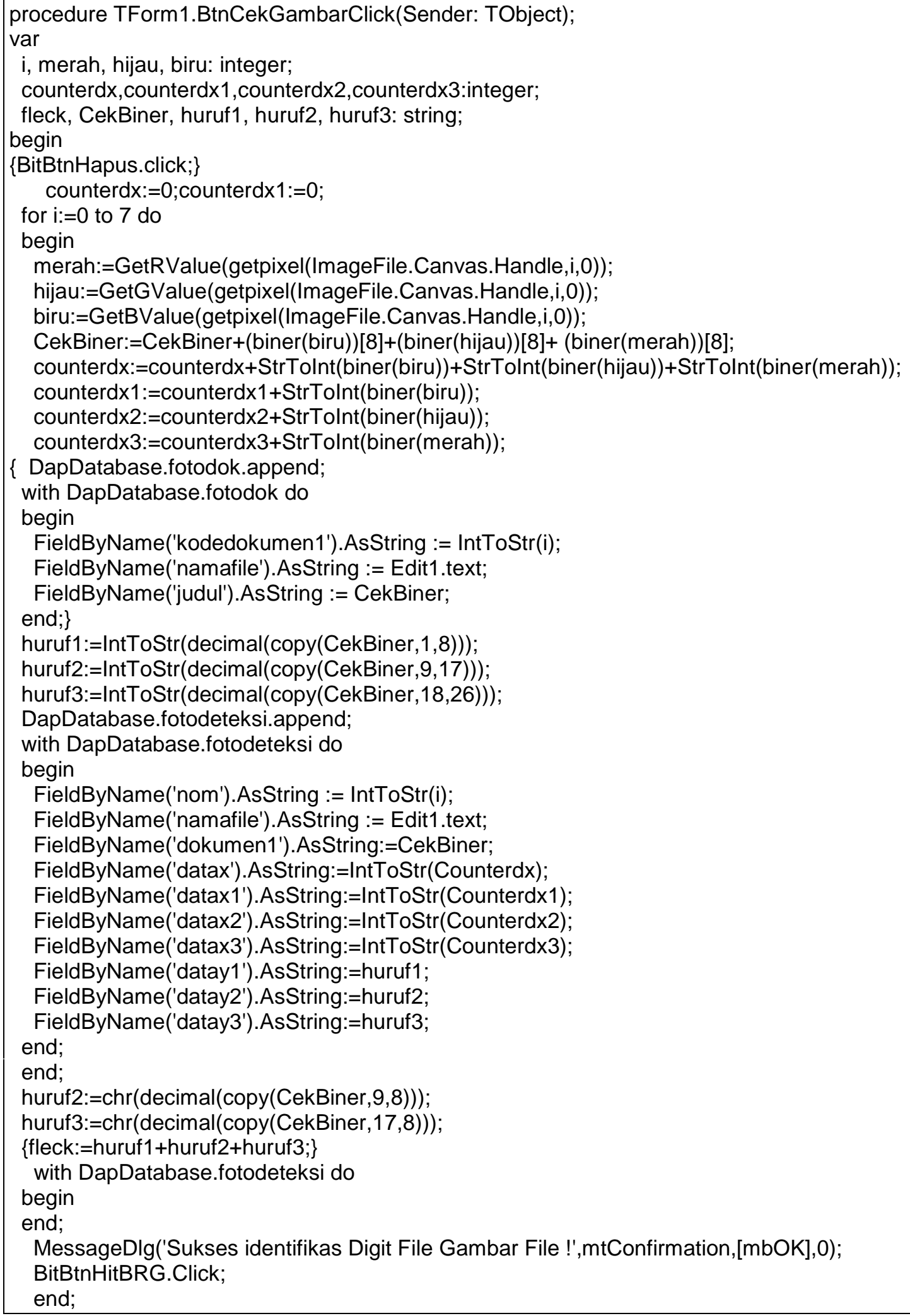


Tabel 3. Data analysa perhitungan perbandingan modikasi gambar, gray dan gambar asli.

\begin{tabular}{|c|c|c|c|c|c|c|c|c|c|}
\hline namafile & dokumen1 & $\begin{array}{l}\text { ratada } \\
\text { tax }\end{array}$ & ratadatax1 & ratadatax2 & ratadatax3 & $\begin{array}{c}\text { ratada } \\
\text { tay1 }\end{array}$ & $\begin{array}{c}\text { ratadata } \\
\text { y2 }\end{array}$ & ratadatay 3 & $\begin{array}{c}\text { Ry+Gy+ } \\
\text { By }\end{array}$ \\
\hline $\begin{array}{l}\text { D:Ihlanalysisgm } \\
\text { blkontras_bmplc } \\
\text { th-asli- } \\
\text { bmplanakanak.b } \\
\text { mp }\end{array}$ & $\begin{array}{l}1000110011 \\
1011011001\end{array}$ & $\begin{array}{r}14009 \\
0321\end{array}$ & 49508185 & 45454622 & 45127513 & 109 & 8689 & 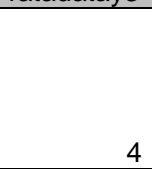 & 8802 \\
\hline $\begin{array}{l}\text { D:Ihlanalysisgm } \\
\text { blkontras_bmplc } \\
\text { th-asli- } \\
\text { bmplanakanakG } \\
\text { ray.bmp }\end{array}$ & $\begin{array}{l}0001110000 \\
0011111111 \\
\end{array}$ & $\begin{array}{r}13635 \\
8556 \\
\end{array}$ & 45452852 & 45452852 & 45452852 & 21 & 584 & 17 & 622 \\
\hline $\begin{array}{l}\text { D:Ihlanalysisgm } \\
\text { blkontras_bmplc } \\
\text { th-asli- } \\
\text { bmplanakanakP } \\
\text { alsu.bmp }\end{array}$ & $\begin{array}{l}0110001101 \\
1100110000\end{array}$ & $\begin{array}{r}14001 \\
9654 \\
\end{array}$ & 49516093 & 45453710 & 45049851 & 77 & 4207 & 2 & 4286 \\
\hline & & & & & & & & & 0 \\
\hline $\begin{array}{l}\text { D:Ihlanalysisgm } \\
\text { blkontras_bmplc } \\
\text { th-asli- } \\
\text { bmplheribis.bmp }\end{array}$ & $\begin{array}{l}0100101111 \\
1100110100\end{array}$ & $\begin{array}{r}14461 \\
67\end{array}$ & 496254 & 495192 & 454721 & 58 & 8896 & 9 & 8963 \\
\hline $\begin{array}{l}\text { D:Ihlanalysisgm } \\
\text { blkontras_bmplc } \\
\text { th-asli- } \\
\text { bmplheribisGray } \\
\text {.bmp }\end{array}$ & $\begin{array}{l}1110001110 \\
0011111100\end{array}$ & $\begin{array}{r}14150 \\
92\end{array}$ & 471697 & 471697 & 471697 & 178 & 5256 & 9 & 5443 \\
\hline $\begin{array}{l}\text { D:lhlanalysisgm } \\
\text { blkontras_bmplc } \\
\text { th-asli- } \\
\text { bmplheribisPals } \\
\text { u.bmp }\end{array}$ & $\begin{array}{l}0011000011 \\
0011011110\end{array}$ & $\begin{array}{r}14247 \\
70 \\
\end{array}$ & 498621 & 495870 & 430278 & 37 & 7528 & 13 & 7578 \\
\hline 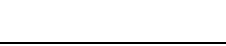 & & & & & & & & & 0 \\
\hline $\begin{array}{l}\text { D:Ihlanalysisgm } \\
\text { blkontras_bmplc } \\
\text { th-asli- } \\
\text { bmplherifrend.b } \\
\text { mp }\end{array}$ & $\begin{array}{l}0001101000 \\
0101010011\end{array}$ & $\begin{array}{r}31634 \\
222 \\
\end{array}$ & 21667451 & 4971574 & 4995197 & 20 & 775 & 7 & 802 \\
\hline $\begin{array}{l}\text { D:Ihlanalysisgm } \\
\text { blkontras_bmplc } \\
\text { th-asli- } \\
\text { bmplherifrendGr } \\
\text { ay.bmp }\end{array}$ & $\begin{array}{l}0000001111 \\
1111100000\end{array}$ & $\begin{array}{r}14935 \\
385\end{array}$ & 4978461 & 4978461 & 4978461 & 2 & 9288 & 0 & 9290 \\
\hline $\begin{array}{l}\text { D:Ihlanalysisgm } \\
\text { blkontras_bmplc } \\
\text { th-asli- } \\
\text { bmplherifrendPa } \\
\text { Isu.bmp }\end{array}$ & $\begin{array}{l}0000011100 \\
1101100100\end{array}$ & $\begin{array}{r}46125 \\
216\end{array}$ & 36148318 & 4986583 & 4990314 & 5 & 1984 & 9 & 1998 \\
\hline & & & & & & & & & 0 \\
\hline
\end{tabular}

Hasil analysis warna tersebut kemudian diolah lagi menjadi rata-rata dari masing-masing warna dengan

Deviasi dapat dihitung dengan perhitungan warna $x$ dan warna $y$

Hitung Deviasi ratawarna $x$ - rata warna y dengan selisih dan

Hitung Selisih Deviasi : (rata-rata warna merah+ rata-rata hijau+ rata-rata warna biru) 
Selisih Rata nilairata warna asli dan warna palsu dengan $>=900$ dan warna palsu dengan warna grayscray $>=4000$ dan warna asli dengan warna grayscale $>=3000$

Tabel 4. Hasil Toleransi Deviasi Warna dan Konstan

\begin{tabular}{|l|r|r|r|r|r|}
\hline \multicolumn{1}{|c|}{ namafile } & $\begin{array}{c}\text { selisih } \\
\text { Gray }\end{array}$ & & $\begin{array}{c}\text { selisihgray/ } \\
\text { ratadatax }\end{array}$ & konstanta & $\begin{array}{c}\text { selisin } \\
\text { kedekatan }\end{array}$ \\
\hline $\begin{array}{l}\text { D:Ihlanalysisgmblkontras_bmplct } \\
\text { h-asli-bmplanakanak.bmp }\end{array}$ & 3731765 & 37.5399633 & 37.5399633 & 38.0282 & 0.48821 \\
\hline $\begin{array}{l}\text { D:Ihlanalysisgmblkontras_bmplct } \\
\text { h-asli-bmplanakanakGray.bmp }\end{array}$ & $\begin{array}{r}13635980 \\
0\end{array}$ & 0.99999088 & 0.99999088 & 1.06506 & 0.06507 \\
\hline $\begin{array}{l}\text { D:Ihlanalysisgmblkontras_bmplct } \\
\text { h-asli-bmplanakanakPalsu.bmp }\end{array}$ & 3661098 & 38.2452625 & 38.2452625 & 38.9634 & 0.71818 \\
\hline & & & & & \\
\hline $\begin{array}{l}\text { D:Ihlanalysisgmblkontras_bmplct } \\
\text { h-asli-bmplheribis.bmp }\end{array}$ & 31075 & 46.5379566 & 46.5379566 & 46.8885 & 0.3505 \\
\hline $\begin{array}{l}\text { D:Ihlanalysisgmblkontras_bmplct } \\
\text { h-asli-bmplheribisGray.bmp }\end{array}$ & 1425978 & 0.99236594 & 0.99236594 & 1.02767 & 0.03531 \\
\hline $\begin{array}{l}\text { D:Ihlanalysisgmblkontras_bmplct } \\
\text { h-asli-bmplheribisPalsu.bmp }\end{array}$ & 9678 & 147.2174 & 147.2174 & 148.195 & 0.9778 \\
\hline & & & & & \\
\hline $\begin{array}{l}\text { D:Ihlanalysisgmblkontras_bmplct } \\
\text { h-asli-bmplherifrend.bmp }\end{array}$ & 16698837 & 1.89439672 & 1.89439672 & 1.9604 & 0.066 \\
\hline $\begin{array}{l}\text { D:Ihlanalysisgmblkontras_bmplct } \\
\text { h-asli-bmplherifrendGray.bmp }\end{array}$ & 14953965 & 0.99875752 & 0.99875752 & 0.99897 & 0.00022 \\
\hline $\begin{array}{l}\text { D:Ihlanalysisgmblkontras_bmplct } \\
\text { h-asli-bmplherifrendPalsu.bmp }\end{array}$ & 31189831 & 1.47885431 & 1.47885431 & 1.48929 & 0.01044 \\
\hline & & & & & \\
\hline
\end{tabular}

perubahan gambar pada warna dinyatalan termodifikasi bila toleransi dan konstanta tidak banyak selisihnya pada tolernasi mendekati 0.5 dan konstanta selisih diantara 2 sampai 20 sangat mendekati dianggap termodifikasi.

\section{KESIMPULAN}

Gambar yang terdiri dari warna-warna dapat diidentifkasi dengan warna dasar RGB (Red, Green, Blue) untuk mengetahui gambar tersebut termodifikasi atau tidak dengan menghitung setiap rata-rata RGB dan kesemuanya dijumlah apakah mendekati warna palsu dari masing-masing warna baik wana dasar warna grayscray maupun konstan dan selisih kedekatannya dapat dibandingkan maka didapat masing-masing rata-rata tersebut menjadi suatu deviasi dengan menghitung selisih dari gambar asli, gambar grayscale dan gambar yang termodifikasi. Sebaliknya apabila jauh dari perbandingan gambar asli, grayscale dan termodifikasi maka gambar sudah dapat dipastikan termodifikasi. 


\section{DAFTAR PUSTAKA}

Heriyanto, Jurnal Telematika Volume 9 No. 1, Juli 2012 ISSN 1829-667X Lu, G, 1999, Multimedia Database Manajemen Systems, Artech House, Inc Subrahmanian, V.S, Principles of Multimedia Databases System 